\title{
LIFE FORMS AND GEOGRAPHICAL DISTRIBUTION OF LICHENS URBAN ECOSYSTEM OF THE CITY OF TIMASHEVSK KRASNODAR TERRITORY
}

\begin{abstract}
Аннотация. Лишайники являются важным компонентом фитоценозов, они участвуют в создании микроклимата сообществ, заселяют малопригодные для других организмов места обитания, выделяют лишайниковые кислоты, задерживающие рост некоторых растений и др. В статье приведены результаты таксономического, географического и экологического анализа лихенобиоты города Тимашевска. На территории урбоэкосистемы выявлен 51 вид лишайников, принадлежащих к 27 родам, 12 семействам, 2 классам. Выявлены жизненные формы лишайников урбоэкосистемы. Один из методов оценки качества атмосферного воздуха основан на использовании видового состава лихенобиоты изучаемой урбоэкосистемы и установлении чувствительности видов. Наличие списка видов лишайников как для всей урбоэкосистемы, так и для отдельных ее участков позволяет достаточно надежно оценить состояние воздушного бассейна района и провести сравнение качества воздуха частей обследованной территории. По итогам проведенных исследований сделан вывод о возможности использования лишайников для долгосрочного мониторинга за состоянием атмосферной среды урбанизированных территорий Северо-Западного Кавказа.

Ключевые слова: урбоэкосистема; лихенобиота; таксономический; географический анализ; жизненные формы.
\end{abstract}

Abstract. Lichens are an important component of phytocenosis since they take part in formation of plant community microclimate, inhabit areas hardly suitable for other organisms, secret acids which retard the growth of some plants, etc. The article presents the results of taxonomic, geographic and environmental analysis of lichen biota in Timashevsk, Krasnodar Krai, Russia. The urban ecosystem accomodates 51 lichen species which belong to 27 genera, 12 families, and 2 groups. Life forms of lichens were detected in urban ecosystem. One of the methods of atmospheric air quality assessment is based on the usage of species composition of lichen biota in the studied urban ecosystem, and on defining of sensitivity of species. The list of lichens for the whole urban ecosystem, as well as for its particular areas, helps provide a solid assessment of the condition of air basin in this area, and compare the air quality on the parts of the explored territory. Therefore, lichens can be used as a bioindicator for long-term surveillance of atmospheric environment in urbanized territories of the North-West Caucasus. Key words: urban ecosystem; lichen biota; taxonomic analysis; geographic analysis; life form.

Сведения об авторах: Криворотов Сергей Борисович, SPIN-код: 6869-9628, д-р биол. наук, Кубанский государственный университет. г. Краснодар, Россия, s.krivorotov_2002@rambler.ru; Манилова Ольга Юрьевна, SPIN-код: 7284-6827, ORCID 0003-2865-9037, канд. биол. наук, Кубанский государственный медицинский университет, г. Краснодар, Россия, manilova27@rambler.ru

About the authors: Krivorotov Sergey Borisovich, SPIN-код: 6869-9628, Dr. habil., Kuban State University, Krasnodar, Russia, manilova27@rambler.ru; Manilova Olga Yurievna, SPIN-код: 7284-6827, ORCID 0003-2865-9037, PhD., Kuban State Medical University, Krasnodar, Russia, manilova27@rambler.ru.

Одним из основных и перспективных методов биоиндикации является лихеноиндикация, позволяющая дать объективную оценку загрязнению атмосферного воздуха на урбанизированных территориях. Основными источниками загрязнения атмосферного воздуха являются автотранспорт, а также различные производственные объекты, поллютанты от которых распространяются на многие десятки километров $[1$, с. $96 ; 13$, с. 2$]$.

Оценить качество атмосферного воздуха урбоэкосистемы можно, используя данные о видовом составе лихенобиоты, а также выявив чувствительность видов лишайников к различным поллютантам. Видовой состав лишайников урбоэкосистемы или ее участков обеспечивает надежность оценки состояния воздушной среды изучаемого района и дает возможность сравнивать качество воздуха отдельных частей территории [7, с. $17 ; 12$, с. 170$]$.

Современные литературные данные указывают на то, что анализ среды урбанизированных территорий проводится лишь в отдельных регионах России. Имеются данные об исследованиях, проводи- 
мых в республике Калмыкия, Челябинской области, на Урале, в Новосибирской области, Красноярском и Алтайском крае. В своих исследованиях авторы рассматривают особенности лишайниковых слоевищ накапливать поллютанты, тем самым оценивать состояние атмосферного воздуха урбоэкосистем быстро и экономично. Перспективность использования метода лихеноиндикации обусловлена тем, что лишайниковые слоевища активно накапливают тяжелые металлы. А именно тяжелые металлы и являются основными поллютантами, интенсивность распространения которых зависит от ряда факторов, в том числе и от техногенеза. Краснодарский край характеризуется активным развитием промышленности и сельского хозяйства - основных «поставщиков», загрязняющих атмосферу урбоэкосистемы компонентов $[4$, с. $114 ; 8$, с. $178 ; 14$, с. 298$]$.

Город Тимашевск является крупнейшим промышленным центром. Находясь практически в самом центре Краснодарского края, в месте пересечения железнодорожных магистралей, данный населенный пункт имеет достаточно выгодное географическое расположение. Указанное местоположение ведет к быстрым темпам роста промышленности при минимальных затратах. Большая часть города представлена промышленными зонами. Интенсивное увеличение производственных и перерабатывающих отраслей положительно влияет на развитие города, обеспечивает высокий уровень жизни населения, но с другой стороны, отрицательно сказывается на экологической обстановке [9, с. $210 ; 11$, с. 80].

В результате проведенных на территории урбоэкосистемы исследований нами составлен аннотированный таксономический список лишайников города Тимашевска и прилегающих территорий. Все выявленные виды лишайников пренадлежат 2 классам - Lecanoromycetes и Arthoniomycetes. При этом 8 семейств и 5 порядков насчитывает класc Lecanoromycetes, 1 порядок и 2 семейства - класс Arthoniomycetes.

Таксономический список составлен с учетом современной номенклатуры, при этом использовался целый ряд монографических работ $[2 ; 3 ; 5$, с. $4 ; 10]$.

Сбор и идентификация лишайников осуществлялись согласно общепринятым методикам [6], анализ жизненных форм и географический анализ проводились по методике, предложенной Н.С. Голубковой (1983).

Лихенобиота изучаемой урбоэкосистемы насчитывает 51 вид, относящихся к 27 родам и 12 семействам (рис. 1).

Рода в семействах распределены следующим образом: по 2 рода в семействах Lecanoraceae и Candelariaceae, по 3 рода в семействах Teloschistaceae и Physciaceae, максимальное количество - 10 родов насчитывает семейство Parmeliaceae. По 1 роду насчитывают 7 семейств.

Среднее количество видов в семействе составляет 4,2. Максимальным видовым разнообразием характеризуются четыре семейства: Parmeliaceae (13 видов), Lecanoraceae (12), Teloschistaceae (6), Physciaceae (5). На долю указанных семейств приходится 70,6\% всего видового состава.

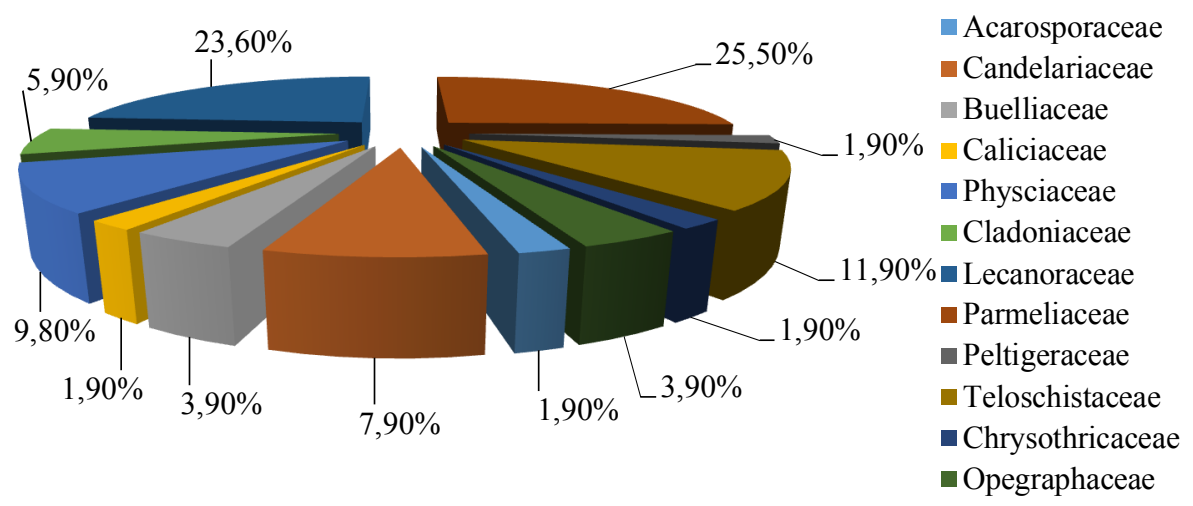

Рис. 1. Структура лихенобиоты урбоэкосистемы города Тимашевска, \%

Среднее количество видов в роде - 1,9. Минимальное видовое разнообразие характерно для 16 родов. Видовым составом выше среднего уровня характеризуются 11 родов: Lecanora (10), Candelariella (3), Physcia (3), Cladonia (3), Parmotrema (3), Caloplaca (3), Buellia (2), Lecidella (2), Melanelixia (2), Xanthoria (2), Opegrapha (2).

Наиболее богаты видами 11 родов (68,64\% видового состава). Они имеют важное значение в формировании лихеносинузий урбоэкосистемы.

Лихенобиота урбоэкосистемы города Тимашевска была подвергнута географическому анализу, она представлена 6 географическими элементами. 
На исследуемой территории максимальное число видов лишайников относится к мультирегиональному элементу. Голарктический тип ареала включает в себя 43,15\% видов, неморальный $11,77 \%$, бореальный - 7,84\% (рис. 2).

Представители неморального элемента с паннеморальным типом ареала составляют 9,8\% от всего видового состава. Эвриголарктический элемент с голарктическим типом ареала и мультирегиональный элемент с бореальным типом ареала включают в себя по 7,84\% видов.

На долю неморального географического элемента с европейским типом ареала и бореального географического элемента с панбореальным типом ареала приходится по 3,92\%.

Минимальное количество видов лихенобиоты включает монтанно-гипоарктический элемент с голарктический типом ареала, бореальный элемент с голарктическим типом ареала, неморальный элемент с голарктическим и евразиатским типами ареала, ното-бореальный элемент с биполярным типом ареала, мультирегиональный элемент с панбореальным типом ареала.

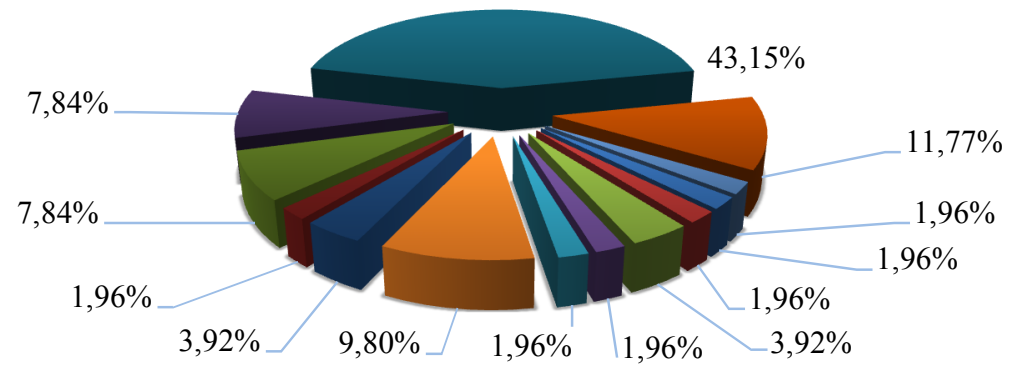

Монтанно-гипоарктический голарктический Бореальный голарктический

Бореальный панбореальный

- Неморальный евразиатский

- Неморальный европейский

- Эвриголарктический голарктический

- Мультирегиональный голарктический

Мультирегиональный панборельный

- Неморальный голарктический

Неморальный паннеморальный

- Ното-бореальный биполярный

- Мультирегиональный бореальный

- Мультирегиональный неморальный

Рис. 2. Географические элементы лихенобиоты урбоэкосистемы города Тимашевска, \%

Таким образом, лихенобиота изучаемой территории является мультирегиональной с голарктическим типом ареала. Был проведен анализ жизненных форм лихенобиоты города Тимашевска и его окрестностей. Механизмы приспособления, возникающие у живых организмов, в том числе и лишайников, обеспечивают выживаемость видов и адаптацию к различным экологическим характеристикам территорий. Виды лишайников, слоевища которых произрастают на поверхности субстрата, относятся к отделу эпигенные лишайников.

Тип плагиотропных лишайников включает в себя класс накипные, и насчитывает 25 видов (49,01\%). Слоевище этих лишайников срастается с субстратом практически всей нижней поверхностью. Группа однообразно-накипных лишайников включает 25 видов $(49,01 \%)$. К данной группе относятся виды, у которых слоевище имеет вид корочки, равномерной в центральной части (рис. 3).
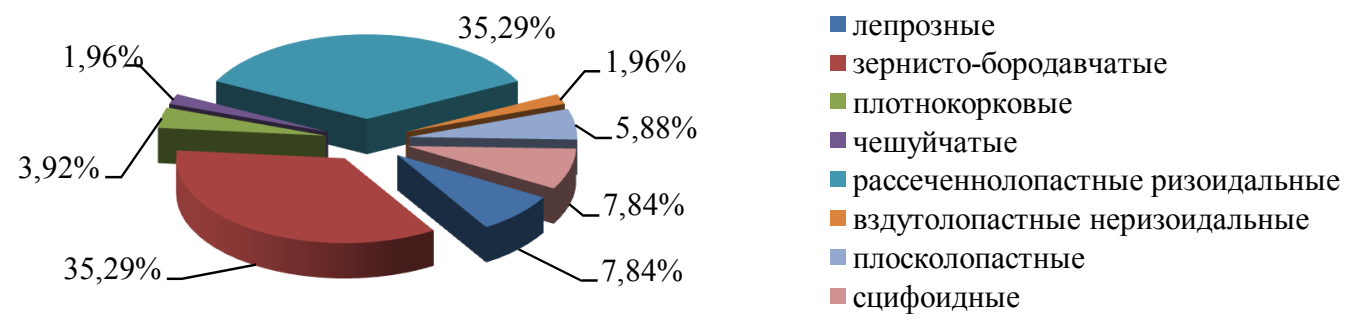

Рис. 3. Жизненные формы лишайников урбоэкосистемы города Тимашевска, \%

К подгруппе лепрозные лишайники относятся 4 вида (7,84\%). На исследуемой территории подгруппа лепрозных лишайников представлена родами Caloplaca, Chrysothrix. Они распространены в парковой, центральной и пригородной зонах; редко представители данной группы встречаются на коре форофитов вблизи транспортных магистралей. Произрастают на коре: вишни обыкновенной, гледичии трехколючковой, дуба черешчатого, тополя пирамидального и других форофитов.

Лишайники, относящиеся к подгруппе зернисто-бородавчатая жизненная форма, насчитывают 18 видов (35,29\%). Данная подгруппа включает рода: Calicium, Lecanora, Candelariella, Lecidella, Opegrapha, Rinodina. Представители этих родов распространены на всей территории города Тимашевска и в 
его окрестностях. Произрастают на коре форофитов: дуба черешчатого, тополя пирамидального, гледичии трехколючковой, айланта высочайшего, ореха грецкого, чёрного, ивы белой и др.

К подгруппе плотнокорковые лишайники относятся 2 вида (3,92\%). Данная подгруппа представлена одним родом - Buellia. Виды рода Buellia распространены в пригородной, парковой, центральной зонах города. Обнаружены на коре рябины, дуба черешчатого, груши обыкновенной, вяза гладкого, гледичии трехколючковой, ясеня высокого.

К подгруппе чешуйчатые относится всего 1 вид $(1,96 \%)$ из рода Acarospora. Обнаружен в пригородной зоне на песчаниках.

На долю класса листоватые лишайники приходится 19 видов (37,25\%). Данная группа характеризуется уплощённым в дорзовентральном направлении слоевищем, которое прикрепляется ризоидами, ризинами или участками нижней поверхности.

Группа рассеченнолопастных ризоидальных лишайников включает 18 видов $(35,29 \%$ от общего количества видов). На изучаемой территории и в ее окрестностях обнаружены следующие роды лишайников, входящие в состав указанной группы: Flavoparmelia, Candelaria, Flavopunctelia, Melanelixia, Melanohalea, Parmelia, Parmotrema, Platismatia, Pleurosticta, Peltigera, Physcia, Rusavskia, Xanthoria. Эта группа имеет максимальное видовое разнообразие, ее представители произрастают на всей территории урбоэкосистемы и в ее окрестностях. Обнаружены на дубе черешчатом, иве белой, гледичии трехколючковой, березе бородавчатой, вишне обыкновенной, ясене высоком, робинии ложноакации, а также других форофитах.

Группа вздутолопастных неризоидальных лишайников насчитывает лишь 1 вид (1,96\%). Данная группа включает лишайники, у которых слоевище имеет лопасти вееровидно-разветвленной формы, и внутри с небольшой полостью. Представитель группы Hypogymnia physodes обнаружен в пригородной и парковой зонах на дубе черешчатом и клене полевом.

К типу ортотропные классу кустистые жизненные формы относятся 7 видов $(13,72 \%)$. Эти лишайники имеют слоевища в виде кустиков, с повисающими, прямостоячими или стелющимися по субстрату лопастями.

К подгруппе плосколопастных лишайников относятся 3 вида (5,88\%), которые принадлежат к 3 родам: Anaptychia, Evernia, Pseudevernia. Виды этих родов распространены в центральной, пригородной, парковой зонах, произрастают на коре: гледичии трехколючковой, дуба черешчатого, клена полевого, ясеня высокого, боярышника обыкновенного, а также других форофитов.

К подгруппе сцифоидные лишайники относятся 4 вида (7,84\%). Эти лишайники имеют слоевища сцифоидной формы, слабо разветвленные. Указанная жизненная форма на исследуемой территории представлена родом Cladonia.

Отдел эпигенных лишайников является основным, к которому относятся все виды, обнаруженные на исследуемой территории и в ее окрестностях. Представители данного отдела имеют слоевище, развивающееся на поверхности субстрата.

Первое место по многообразию видов принадлежит группе плагиотропных листоватых рассеченнолопастных ризоидальных лишайников $(35,29 \%)$, а также группе плагиотропных однообразнонакипных зернисто-бородавчатых лишайников $(35,29 \%)$. Второе место - группе плагиотропных однообразно-накипных лепрозных и ортотропных чешуйчато-кустистых сцифоидных лишайников $(7,84 \%)$. Третье место занимают ортотропные кустистые повисающие плосколопастные жизненные формы лишайников $(5,88 \%)$.

Плагиотропные накипные однообразно-накипные плотнокорковые лишайники представлены небольшим количеством видов (3,92\%).

Минимальным количеством видов представлены плагиотропные однообразно-накипные чешуйчатые $(1,96 \%)$ и плагиотропные листоватые вздутолопастные неризоидальные жизненные формы лишайников $(1,96 \%)$.

\section{ЛИТЕРАТУРА}

1. Божко А. А. Лихеноиндикация-метод объективного тестирования техногенной нагрузки урбанизированых экосистем // Фундаментальные исследования. 2004. № 3. С. 95-97.

2. Бязров Л. Г., Криволуцкий Д. А. Лишайники в экологическом мониторинге. М.: Научный мир, 2002.

3. Голубкова Н. С. Анализ флоры лишайников Монголии. Л.: Наука, 1983. 248 с.

4. Иржигитова Д. М., Корчиков К. Е. С. Некоторые химические особенности коры деревьев как субстрата для развития лишайников (на примере Красносамарского лесного массива) // Вестник Самарского государственного университета. 2011. № 5(86). С. 114-152.

5. Криворотов С. Б. Лишайники и лишайниковые группировки Северо-Западного Кавказа и Предкавказья: Флористический и экологический анализ: Автореф. дис. ... д-ра биол. наук. Краснодар, 2001. 35 с. 
6. Окснер А. Н. Определитель лишайников СССР. Морфология, систематика и географическое распространение. Л.: Наука, 1974.

7. Плюснин С. Н. Лихеноиндикация: основные подходы // Вестник Института биологии Коми НЦ УрО РАН. 2012. № 7. C. 17-19.

8. Пчелкин А. В., Пчелкина Т. А. Восстановление локальных популяций редких видов лишайников в условиях мегаполиса // Проблемы популяционной биологии: Мат-лы XII всеросс. популяционного семинара памяти Н. В. Глотова. Йошкар-Ола, 2017. С. 177-179.

9. Радиков М. И. Соредии лишайников как индикаторы состояния атмосферы городов // Принципы и способы сохранения биоразнообразия: Сб. мат-лов 2 всероссийской науч. конф. (Йошкар-Ола, 28-31 января). Йошкар-Ола, 2006. C. 210-212.

10. Урбанавичюс Г. П. Список лихенофлоры России. СПб.: Наука, 2010.

11. Щербакова А. И. Лишайники с высокой антиоксидантной активностью // Вестник Поволжского государственного технологического университета. Серия: Лес. Экология. Природопользование. 2018. № 4(40). С. 75-84. https://doi.org/ $10.15350 / 2306-2827.2018 .4 .75$

12. McMullin R. T., Lendemer J. C., Braid H. E., Newmaster S. G. Molecular insights into the lichen genus Alectoria (Parmeliaceae) in North America // Botany. 2016. Vol. 94. № 3. P. 165-175. https://doi.org/10.1139/cjb-2015-0186

13. Nordin A., Moberg R., Tønsberg T., Vitikainen O., Dalsätt A., Myrdal M., Ekman S. Santesson's checklist of Fennoscandian lichen-forming and lichenicolous fungi // Ver. April. 2011. Vol. 29. P. 2011.

14. Zhao X., Leavitt S. D., Zhao Z. T., Zhang L. L., Arup U., Grube M., Divakar P. K. Towards a revised generic classification of lecanoroid lichens (Lecanoraceae, Ascomycota) based on molecular, morphological and chemical evidence // Fungal Diversity. 2016. Vol. 78. № 1. P. 293-304. https://doi.org/10.1007/s13225-015-0354-5

\section{REFERENCES}

1. Bozhko, A. A. (2004). Likhenoindikatsiya-metod ob"ektivnogo testirovaniya tekhnogennoi nagruzki urbanizirovanykh ekosistem. Fundamental'nye issledovaniya, (3), 95-97. (in Russian)

2. Byazrov, L. G., \& Krivolutskii, D. A. (2002). Lishainiki v ekologicheskom monitoringe. Moscow. Nauchnyi mir. (In Russian)

3. Golubkov, N. With. (1983). Analysis of Mongolian lichen flora. Leningrad. (in Russian)

4. Irzhigitova, D. M., \& Korchikov, K. E. S. (2011). Nekotorye khimicheskie osobennosti kory derev'ev kak substrata dlya razvitiya lishainikov (na primere Krasnosamarskogo lesnogo massiva) [Some chemical characteristics of Bark as a substrate for Lichen's developing (Krasnosamarsky Forest as an Example)]. Vestnik Samarskogo gosudarstvennogo universiteta [Natural science series], 5(86). 114-152. (in Russian)

5. Krivorotov, S. B. (2001). Lishainiki i lishainikovye gruppirovki Severo-Zapadnogo Kavkaza i Predkavkaz'ya (Floristicheskii i ekologicheskii analiz). (in Russian)

6. Oksner, A. N. (1974). Opredelitel' lishainikov SSSR. Morfologiya, sistematika i geograficheskoe rasprostranenie. V. Leningrad. (in Russian)

7. Plyusnin, S. N. (2012). Lichen-indications: basic approaches. Vestnik Instituta biologii Komi NTs UrO RAN, (7), 17-19. (in Russian)

8. Pchelkin, A. V., \& Pchelkina, T. A. (2017). Vosstanovlenie lokal'nykh populyatsii redkikh vidov lishainikov v usloviyakh megapolisa. In Problemy populyatsionnoi biologii. Mat-ly XII vseross. populyatsionnogo seminara pamyati N. V. Glotova. Ioshkar-Ola, 177-179. (in Russian)

9. Razikov, M. I. (2006). Sorediya lichens as an indicator of the state of the atmosphere of cities. In Principles and methods of biodiversity conservation: proceedings of the 2 scientific conferences, Yoshkar-Ola, 210-212. (in Russian)

10. Urbanavichyus, G. P. (2010). Spisok likhenoflory Rossii [A checklist of the lichen flora of Russia].

11. Shcherbakova, A. I. (2018). Lishainiki s vysokoi antioksidantnoi aktivnost'yu [Lichens with high antioxidant activity]. Vestnik Povolzhskogo gosudarstvennogo tekhnologicheskogo universiteta. Seriya: Les. Ekologiya. Prirodopol'zovanie [Bulletin of the Volga state technological University: Forest. Ecology. Nature management], (4(40)). 75-84. (in Russian) https://doi.org/10.15350/2306-2827.2018.4.75

12. McMullin, R. T., Lendemer, J. C., Braid, H. E., \& Newmaster, S. G. (2016). Molecular insights into the lichen genus Alectoria (Parmeliaceae) in North America. Botany, 94(3), 165-175. https://doi.org/10.1139/cjb-2015-0186

13. Nordin, A., Moberg, R., Tønsberg, T., Vitikainen, O., Dalsätt, A., Myrdal, M., ... \& Ekman, S. (2011). Santesson’s checklist of Fennoscandian lichen-forming and lichenicolous fungi. Ver. April, 29, 2011.

14. Zhao, X., Leavitt, S. D., Zhao, Z. T., Zhang, L. L., Arup, U., Grube, M., ... \& Divakar, P. K. (2016). Towards a revised generic classification of lecanoroid lichens (Lecanoraceae, Ascomycota) based on molecular, morphological and chemical evidence. Fungal Diversity, 78(1), 293-304. https://doi.org/10.1007/s13225-015-0354-5

Криворотов С. Б., Манилова О. Ю. Жизненные формы и географическое распространение лишайников урбоэкосистемы города Тимашевска Краснодарского края // Вестник Нижневартовского государственного университета. 2020. № 1. C. 10-14. https://doi.org/10.36906/2311-4444/20-1/02

Krivorotov S. B., \& Manilova O. Yu. (2020). Life forms and geographical distribution of lichens urban ecosystem of the city of Timashevsk Krasnodar territory. Bulletin of Nizhnevartovsk State University, (1). 10-14. (In Russian) https://doi.org/10.36906/2311-4444/20-1/02 